\title{
Cast-in-place, ambiently-dried, silica-based, high-temperature insulation
}

\author{
Eric Jianfeng Cheng ${ }^{\text {a }}$, Jeff Sakamoto ${ }^{\text {a }}$, James Salvador ${ }^{\mathrm{b}}$, Hsin Wang ${ }^{\mathrm{c}}$, \\ Ryan Maloney ${ }^{\mathrm{d}, *}$, and Travis Thompson ${ }^{\mathrm{a}, *}$ \\ ${ }^{a}$ Department of Mechanical Engineering, University of Michigan, Ann Arbor, MI 48109, USA \\ ${ }^{\mathrm{b}}$ Chemical \& Materials Systems Lab, GM Global Research \& Development, \\ MC 480-106-224, 30500 Mound Road, Warren, MI 48090, USA \\ ${ }^{c}$ Oak Ridge National Laboratory, Oak Ridge, TN 37831, USA \\ d Department of Chemical Engineering and Materials Science, Michigan State University, MI 48824,
} USA

\begin{abstract}
A novel sol-gel chemistry approach was developed to enable the simple integration of a cast-inplace, ambiently-dried insulation into high temperature applications. The insulation was silicabased and synthesized using methyltrimethoxysilane (MTMS) as the precursor. MTMS created a unique silica microstructure that was mechanically robust, macroporous, and superhydrophobic. To allow for casting into and around small, orthogonal features, zirconia fibers were added to increase stiffness and minimize contraction that could otherwise cause cracking during drying. Nano-sized titania powder was incorporated as an opacifier to reduce radiative heat transport. To assess relevance to high temperature thermoelectric generator technology, a comprehensive set of materials characterization experiments were conducted. The silica gel was thermally stable, retained superhydrophobicity with a water contact angle $>150^{\circ}$, and showed a high electrical resistance $>1 \mathrm{G}$ ohm, regardless of heating temperature (up to $600{ }^{\circ} \mathrm{C}$ in Ar for $4 \mathrm{~h}$ ). In addition, The silica-based thermal insulation exhibited a Young's modulus $\sim 3.7 \mathrm{MPa}$ and a low thermal conductivity $<0.08 \mathrm{~W} /(\mathrm{m} . \mathrm{K})$ at room temperature before and after heat treatment (up to $600{ }^{\circ} \mathrm{C}$ in Ar for $4 \mathrm{~h}$ ). Thus, based on the simplicity of the manufacturing process and the optimized material properties, we believe this technology can act as an effective cast-in-place thermal
\end{abstract}


insulation (CTI) for thermoelectric generators and myriad other applications requiring improved thermal efficiency.

*Corresponding authors.

E-mail address: rmaloney707@gmail.com (Ryan Maloney).

E-mail address: thom@umich.edu (Travis Thompson).

\section{Introduction}

Diminishing fossil fuel supplies require improved energy efficiency [1]. In the United States, approximately $60 \%$ of the energy converted from fossil fuels is currently rejected as waste heat while only $40 \%$ is serviceable [2]. Clearly, there is a compelling need for waste heat recovery technology. One approach involves the development of thermoelectric generators (TEGs) to convert waste heat from combustion directly to electrical energy [3]. For example, efforts are underway to integrate TEG technology into internal combustion engine (ICE) exhaust systems to convert waste heat in the exhaust gas into electricity. The electricity could then be used to improve fuel efficiency by reducing the load on or eliminating the need for an alternator, which requires mechanical energy from the ICE.

TEG technology typically consists of semiconducting elements, which convert a heat flux into a DC voltage that can be used to drive an external load, and a heat management system whereby thermal insulation is needed to reduce parasitic heat loss [3, 4]. At present, aerogel-based insulation is under development for space TEG technology [5]. Aerogel was first produced in the 1930s [6], and is a unique class of materials exhibiting high specific surface area (200-1200 $\left.\mathrm{m}^{2} / \mathrm{g}\right)$, high porosity $(80-99 \%)$, low density $\left(<0.05 \mathrm{~g} / \mathrm{cm}^{3}\right)$ and low thermal conductivity $(<0.02$ $\mathrm{W} /(\mathrm{m} . \mathrm{K}))$ [7-11]. When prepared using silica or carbon, aerogel can achieve the lowest thermal conductivity $(<0.01 \mathrm{~W} /(\mathrm{m} . \mathrm{K})$ at $298 \mathrm{~K})$ of any material, making it an appealing candidate for 
thermal insulation [7]. However, to achieve aggressive cost targets for industrial and automotive applications requiring high temperature insulation, an alternative material approach to aerogel is required for several reasons: 1) aerogel is typically prepared using a supercritical drying process which can complicate and/or prohibit large volume production of bulk insulation and/or integration into TEG technology, 2) aerogel is inherently brittle, thus it may not survive applications involving vibrations and shock, 3) infrared radiation (IR) is the dominant heat transport mechanism in high porosity ceramic materials, and 4) typically high surface area materials absorb substantial amounts of water, causing corrosion upon thermal cycling in ambient air. In short, developing a low-cost insulation material is the subject of much research worldwide with many different strategies having been proposed, but to date none have had widespread success.

The purpose of this study is to address the challenges listed above for aerogel-based thermal insulation by developing an alternative material approach and tailoring the material specifically for integration into TEG technology. To simplify and reduce cost of aerogel-based insulation production, one approach is to synthesize a porous, silica-based gel using an ambient drying process. The most common approach to ambiently dry porous silica involves a combination of exchanging the pore fluid with a low-tension solvent and treating the surface with a silylating agent to reduce surface tension. Such a route has been systematically explored by A. Venkateswara Rao and A. Parvathy Rao et al., who reported the effects of various solvents and surface modifications on ambiently-dried silica gels $[12,13]$. Such methods can produce high quality monoliths, but a few challenges remain. First, the additional processing steps involved in exchanging the pore fluid and chemically modifying the surface can add significant time and cost. This has been somewhat alleviated by Schwertfeger et al. who developed a single-step process 
for surface treatment and solvent exchange using a mixture of hexamethyldisiloxane (HMDSO) and trimethylchlorosilane (TMCS) [14]. The second issue is that such drying techniques typically rely on the so-called "spring-back" effect, where $>40 \%$ contraction of the gel's initial wet volume occurs before expanding back to near its original volume $[8,15,16]$. While such a technique is perfectly suitable for monoliths, reliance on spring-back precludes the use of ambiently-dried silica gel as a cast-in-place insulation material in applications with complex geometries or rigid inclusions. In such instances, the gel will crack and break apart during the initial high-shrinkage phase of drying before spring-back occurs. Another strategy is to reinforce the gel network with short fibers, or to react a cross-linked polymer on the silica surface [17-19]. However, both approaches still depend on some degree of spring-back effect, and the polymeric coating is not stable at high temperatures $\left(>500^{\circ} \mathrm{C}\right)$.

This work details the synthesis of a porous silica using MTMS as the sol-gel precursor. Preventing spring-back and reducing radiative heat transport were a specific focus for the reasons explained above. MTMS was first explored as an alkoxide for the synthesis of supercritically-dried aerogel by Hegde et al. [20], but an ambient drying technique was never reported. Baghat et al. described the ambient drying of acid-base catalyzed MTMS gels, but reported that the gels underwent spring-back effect during drying [21].

In this study, the MTMS-derived silica network was robust and consisted of macropores. In addition, the incorporation of fibers and mineral powders effectively eliminated the spring-back effect. Owing to its high albedo, titania powder was integrated as an IR scattering medium (illustrated in Fig. 1) [22]. Though some measures were taken to optimize the sol-gel chemistry to produce uniform gels that gelled quickly and dried uniformly, the primary emphasis of this article is to describe the material properties such as thermal stability, hydrophobicity, electrical 
conductivity, mechanical properties and thermal conductivity. The results of numerous characterization techniques are discussed and included: electron microscopy, thermogravimetric analysis (TGA), IR spectroscopy, electrochemical impedance spectroscopy (EIS), compression test, and thermal conductivity. Overall, this study presents a novel approach to producing a lowcost, silica-based, high-temperature thermal insulation, with a focus on improving the performance of TEGs through superior thermal management. We believe this material approach could extend to myriad other applications requiring cast-in-place thermal insulation ranging from relatively small microelectronic devices to intermediate-scale automotive components, and perhaps even large-scale power plants.

\section{Experimental}

\subsection{Chemicals}

MTMS $\left(\mathrm{CH}_{3}-\mathrm{Si}\left(\mathrm{OCH}_{3}\right)_{3}, 97 \%\right.$, Alfa Aesar), methanol $\left(\mathrm{CH}_{3} \mathrm{OH}, 99 \%\right.$, Alfa Aesar), ammonium hydroxide $\left(\mathrm{NH}_{4} \mathrm{OH}, 28-30 \% \mathrm{NH}_{3}\right.$, Alfa Aesar) and deionized water $\left(\mathrm{H}_{2} \mathrm{O}\right.$, reverse osmosis) were selected for production of silica gel. Mineral powders: titania (200 nm, Inframat Advanced Materials), fumed silica (85-115 $\mathrm{m}^{2} / \mathrm{g}$, Alfa Aesar) and quartz powder ( $2 \mu \mathrm{m}, 99.5 \%$, Alfa Aesar) were chosen as fillers; titania was used as an IR scattering medium, while fumed silica and quartz powders were used to suspend the nano-sized titania particles in gel solution [19, 23]. Yttria-stabilized zirconia (YSZ) fibers were integrated to increase elastic modulus. Nominal composition of the silica gel, including all chemical solutions and minerals, is shown in Table 1. At temperature $>300{ }^{\circ} \mathrm{C}$, radiative heat transfer dominates the three fundamental heat transfer mechanisms: conduction, convection and radiation (illustrated in Fig. 1(b)). The optimal concentration of titania to reduce radiative heat transfer was found to be $100 \mathrm{mg} / \mathrm{cm}^{3}[19,24]$.

\subsection{Gel processing}


The precursor solution, MTMS, was dispensed using a pipette and placed in a vial. A catalyst solution consisting of methanol, water and ammonium hydroxide was prepared in a separate vial. The two solutions were combined and manually shaken for $30 \mathrm{sec}$ and allowed to rest. After standing for $\sim 30 \mathrm{~min}$, gelation occurred and the resultant gel was aged for $10 \mathrm{~h}$ and then placed in a fume hood and ambiently dried for $24 \mathrm{~h}$ before being extracted from the casting mold. To integrate mineral fibers and powders, zirconia fibers, titania power, fumed silica and quartz particles were added to MTMS solution, which was then combined with the catalyst solution. To achieve uniform dispersion, the solid and liquid constituents were sonicated (Vibra cell ${ }^{\mathrm{TM}}$, Sonics \& Materials Inc., 500/750 Watt, probe diameter $13 \mathrm{~mm}$ ) for $1 \mathrm{~min}$. Zirconia fibers were integrated to increase stiffness; titania powders were added to suppress radiative heat transfer; quartz and fumed silica were used to suspend titania powders and avoid agglomeration of titania particles during gelation.

To test heat treatment effects, as-dried gel samples were placed in an Ar-filled glove box $(<1$ ppm water and oxygen) for 2 days to remove excessive solvent and oxygen. The gels were then placed in a fused silica tube and evacuated to $3.3 \times 10^{-3}$ Torr $(0.44 \mathrm{~Pa})$ and back filled with $\mathrm{Ar}$ twice. The gel samples were subsequently back filled with 200 Torr (26.7 kPa) high-purity Ar and flame-sealed for heat treatment. Three groups of gels were heated to $400{ }^{\circ} \mathrm{C}, 500{ }^{\circ} \mathrm{C}, 600{ }^{\circ} \mathrm{C}$ for $4 \mathrm{~h}$, respectively.

Table 1 Nominal composition of silica gel

\begin{tabular}{l|c|c|c|c|c|c|c}
\hline \multicolumn{4}{c|}{ Starting materials (ml) } & \multicolumn{4}{c}{ Filler minerals (g) } \\
\hline MTMS & Methanol & Water & Ammonia & Titania & Quartz & Fumed Silica & $\mathrm{ZrO}_{2}$ fiber \\
\hline 3.93 & 3.904 & 1.559 & 0.68 & 1 & 0.2 & 0.05 & 0.25 \\
\hline
\end{tabular}




\subsection{Microstructural, chemical, and mechanical characterizations}

Bulk density was measured by dividing geometric volume by weight. Microstructures were observed using a Dualbeam SEM/FIB microscope (FEI Helios Nanolab 650, accelerating voltage: $50 \mathrm{~V}-30 \mathrm{kV}$; beam current: $0.8 \mathrm{pA}-26 \mathrm{nA}$ ). Optical images of gelation, casting, water contact angle, and compression test were taken using a digital camera (G11, Canon). A JEOL 2010F analytical TEM (100 and $200 \mathrm{kV}$ ) was used to observe nano-sized titania particles embedded in the gel network. X-ray diffraction (XRD) was performed on a powder diffractometer (Rigaku 600 Miniflex). Chemical bonding was analyzed using a Renishaw inVia Raman microscope (multiple lasers: $514 \mathrm{~nm}, 633 \mathrm{~nm}, 647 \mathrm{~nm}, 785 \mathrm{~nm} ;<1 \mathrm{~cm}^{-1}$ spectral resolution capability) and a Fourier transform infrared spectroscopy (FTIR) spectrometer in an attenuated total reflection (ATR) mode. Thermogravimetric analysis (TGA) was carried out in Ar on a thermogravimetric analyzer thermobalance (TA Instruments SDTQ600 TGA). Thermal conductivity was measured using a Hot Disk Thermal Constants Analyzers at Oak Ridge National Laboratory (ORNL). Electrical resistance was measured using a digital multimeter (AC/DC Current/Voltage; 1G ohm resistance measure max; 34410 A, Agilent). Electrochemical impedance spectroscopy (EIS) was performed with a Bio-Logic SP200 from $200 \mathrm{~Hz}$ to $7 \mathrm{MHz}$ with a $100 \mathrm{mV}$ perturbation at room temperature, where a fixture was used to hold the gel specimens and electrodes in a stable and constant position. Water contact angle was measured using an optical microscope (LEICA EZ4D, Olympus). Compression behavior was tested on an Instron 5944 Microtester with a 500 N Static Load Cell. The strain rate for the compression test was $1.5 \mathrm{~mm} / \mathrm{min}$; to improve accuracy, parallel faces of the test specimens were ground using precision fixture. All measurements in this study were conducted at room temperature. Thermal conductivity of the gel samples were obtained by a transient plane source (TPS) method, where a double-spiral nickel heater/sensor 
sandwiched between Kapton thin films was used [25]. Each sample was measured for 5 times with scatter less than $\pm 2.5 \%$, and the test parameters were kept the same for all measurements in order to compare changes due to heat treatments. The standard Brunauer-Emmett-Teller (BET) test was carried out using a Micromeritics ASAP-2020M nitrogen adsorption apparatus.

\section{Results and discussion}

\subsection{Gelation of MTMS-derived silica gel and its microstructure}

The gelation behavior is similar to what is observed in silica sol-gel chemistry, but there are some subtle differences (Fig. 2). First, immediately upon combining the sol precursor solutions (10 ml) consisting of MTMS, methanol, ammonium hydroxide and water, the sol was transparent (Fig. 2(a)). In tetraethoxysilane (TEOS) or tetramethoxysilane (TMOS)-based sol-gel chemistry, the solution typically remains optically clear throughout the gelation process. However, the MTMS sol transitioned into an opaque solution as gelation occurred (Fig. 2(b)) and eventually transformed into a rigid monolith (Fig. 2(c)). As discussed in further detail below, the optical clarity of the MTMS sol diminished, as gelation occurred, likely due to silica microstructural features with dimensions that were comparable to the wavelength of light. According to previous work by Rao et al., gelation reaction pathway occurred when the MTMS methoxy groups $\left(-\mathrm{OCH}_{3}\right)$, underwent hydrolysis and condensation as follows [13]:

$$
\begin{gathered}
\mathrm{CH}_{3}-\mathrm{Si}\left(\mathrm{OCH}_{3}\right)_{3}+3 \mathrm{H}_{2} \mathrm{O} \rightarrow \mathrm{CH}_{3}-\mathrm{Si}(\mathrm{OH})_{3}+3 \mathrm{CH}_{3} \mathrm{OH} \\
2 \mathrm{CH}_{3}-\mathrm{Si}(\mathrm{OH})_{3} \rightarrow \mathrm{CH}_{3}(\mathrm{OH})_{2} \mathrm{Si}-\mathrm{O}-\mathrm{Si}(\mathrm{OH})_{2} \mathrm{CH}_{3}+\mathrm{H}_{2} \mathrm{O} \\
\mathrm{CH}_{3}-\mathrm{Si}\left(\mathrm{OCH}_{3}\right)_{3}+\mathrm{CH}_{3}-\mathrm{Si}(\mathrm{OH})_{3} \rightarrow \mathrm{CH}_{3}\left(\mathrm{OCH}_{3}\right)_{2} \mathrm{Si}-\mathrm{O}-\mathrm{Si}(\mathrm{OH})_{2} \mathrm{CH}_{3}+\mathrm{CH}_{3} \mathrm{OH} .
\end{gathered}
$$

Since methoxy groups $\left(-\mathrm{OCH}_{3}\right)$ were hydrolysable, MTMS hydrolyzed first, as in Eq. (1), which was followed by water condensation (Eq. (2)) and/or alcohol condensation (Eq. (3)), resulting in a highly porous 3D silica gel. Second, owing to the methoxy group tethered to the Si in MTMS, 
the surface of the resultant microstructure is terminated with hydrophobic $-\mathrm{CH}_{3}$ groups, giving rise to superhydrophobic behavior (to be discussed in more detail below). SEM micrographs of as-dried CTI are shown in Fig. 3, where the spherical silica particles resembled a pearl-necklace microstructure with an average diameter estimated at $10.7 \pm 2.6 \mu \mathrm{m}$. The silica spheres appeared fused during gelation to form a robust 3D architecture. In general, relatively large pores (microsized) interpenetrated the spherical silica network and ranged from $\sim 3 \mu \mathrm{m}$ (Fig. 3(d)) to $\sim 30 \mu \mathrm{m}$ (Fig. 3(a)). Though the BET average pore size and surface area of the silica gel were determined to be $2.5 \mathrm{~nm}$ and $104 \mathrm{~m}^{2} / \mathrm{g}$, respectively, these results were confined to the limitations of the measurement technique: pores $>100 \mathrm{~nm}$ were not probed. For typical supercritically-dried silica aerogels the average pore size is in the range of $20-40 \mathrm{~nm}$ [8], leading to higher capillary pressure $(p)$, compared to what is found in CTI, according to the Laplace equation $[13,26]$ :

$$
p=\frac{2 \gamma \cos \theta_{c}}{R}
$$

Where $\gamma$ is surface tension of pore liquid, $\theta_{\mathrm{c}}$ is the contact angle between the liquid and pore wall and $R$ is the pore radius (assumed to be cylindrical pores). Thus, in conventional silica sol-gel chemistry, the combination of relatively small pores that create substantial pressure during drying and the lack of organically modified surface chemistry to reduce surface tension requires supercritical drying to eliminate capillary pressure [27-30]. Though micron-sized pores could increase thermal conductivity by facilitating gas diffusion through the gel network, they would effectively reduce capillary forces generated between the liquid and vapor interfaces during ambient drying [31]. Therefore, along with the superhydrophobic surface chemistry, the CTI macropores might be the key factor in reducing capillary forces, thus enabling ambient temperature and pressure drying. 


\subsection{Integration of mineral fibers and powders}

The ambient drying process (after aging process) mainly consisted of two distinct stages. In the first stage, the CTI exhibited a mass loss of approximately 50\%, which caused approximately $5 \%$ volumetric shrinkage (corresponding to $\sim 1.5 \%$ linear shrinkage of diameter; specimens were assumed to be cylindrical) in the first $1.5 \mathrm{~h}$ of drying, as illustrated in Fig. 4(a). In the second stage, an additional $30 \%$ mass loss occurred causing an additional 10\% volumetric shrinkage in the next $2.5 \mathrm{~h}$. No appreciable mass loss or shrinkage was thereafter observed after $4 \mathrm{~h}$ (Fig. 4(a)). Since evaporation is affected by surface energy and surface energy is governed by the liquidsolid interface energy, the first stage of mass loss could be related to methanol evaporation from relatively large pores and mass loss from the second stage was related to methanol evaporation from smaller pores. Overall, the CTI exhibited a maximum of $\sim 15 \%$ volumetric shrinkage without relying on the spring-back effect, solvent exchange, or any post-gelation surface treatment [19], which were essential in previously reported gel drying process under ambient pressure $[12,32,33]$.

Having established a robust porous silica network, further engineering was required to improve the mechanical and thermal insulation properties for integration into TEG technology. First, casting into and around orthogonal features (thermoelectric elements) would cause fracture if the silica network shrank ( $15 \%$ volumetric shrinkage) during drying. Thus YSZ fibers were integrated into the silica gel matrix to increase the elastic modulus and for reinforcement to minimize shrinkage during drying [19]. Second, to reduce IR heat transport, the dominant heat transport mechanism in porous media at temperatures $>300{ }^{\circ} \mathrm{C}$, titania powder was incorporated into the gel matrix. Nano-sized titania was selected, based on its high albedo [22]. To further 
reduce sedimentation and agglomeration of all mineral additives, micron-sized quartz and fumed silica were added to increase the sol PH to more effectively suspend and distribute the titania particles $[19,23]$. In addition, fumed silica and titania particles could also stiffen the gel network and reduce shrinkage during drying [34]. The integration of the reinforcing fibers and mineral particles effectively reduced the volumetric shrinkage of the gel from $\sim 15 \%$ to less than $5 \%$ (corresponding to $\sim 1.5 \%$ final linear shrinkage in diameter), as depicted in Fig. 4(b). Fig. 5 presents optical images of opacified silica gels cast in various molds, shapes and forms after drying. As evidenced by the silica gel-cast, cm-scale, cylindrical mold (Fig. 5(a)), the shrinkage of the diameter of the rod was negligible. In addition, high aspect ratio rods (Fig. 5(b)) and complex features (Fig. 5(c)) were successfully cast, demonstrating good castability of the opacified gel. To determine if the opacified gel exhibited useful mechanical integrity or handleability, a gel specimen was cut into a cube as depicted in Fig. 5(d). The density of the opacified gel was calculated as the ratio between the gel mass and its superficial volume, $\sim 0.367 \mathrm{~g} / \mathrm{cm}^{3}$, which was comparable to other MTMS-derived silica gels $[8,13]$.

To confirm the presence of the mineral compounds and if the MTMS-derived silica network was amorphous, XRD was conducted (Fig. 6(a1, a2)). The XRD pattern of the pure silica network in Fig. 5(a1) shows a typical broad amorphous feature at $2 \theta=21.8^{\circ}$ [35]. The XRD pattern of opacified CTI confirms the presence of titania, silica (quartz) and zirconia (Fig. 6(a2). To characterize the chemical bonding in CTI, Raman spectra of an opacified gel, quartz, fumed silica and titania powders were recorded (Fig. 6(b)). Strong and sharp bands attributable to titania and fumed silica (at $238 \mathrm{~cm}^{-1}, 444 \mathrm{~cm}^{-1}$ and $609 \mathrm{~cm}^{-1}$ ), and a weak but sharp band due to quartz (symmetric Si-O-Si stretching mode at $465 \mathrm{~cm}^{-1}$ ) were observed, respectively. The three intermediate-intensity broad bands in the $185-620 \mathrm{~cm}^{-1}$ region of the Raman spectrum of the 
opacified gel were likely from overlapping of bands of amorphous silica, fumed silica, quartz and titania. Bands at $1414 \mathrm{~cm}^{-1}$ (weak), $2844 \mathrm{~cm}^{-1}$ (weak) $2914 \mathrm{~cm}^{-1}$ (strong), and $2975 \mathrm{~cm}^{-1}$ (strong) corresponded to the bending and stretching modes of methyl groups $\left(-\mathrm{CH}_{3}\right)$ as expected [36].

\subsection{Thermal stability analysis}

The thermal stability of the opacified gels was investigated by heat treatment at $400{ }^{\circ} \mathrm{C}, 500{ }^{\circ} \mathrm{C}$, and $600{ }^{\circ} \mathrm{C}$ in $\mathrm{Ar}$ for $4 \mathrm{~h}$, respectively. Because most TEG devices consist of oxidation sensitive components, it is likely that a cover gas of inert atmosphere, e.g. Ar, will be necessary. Thus, to maintain relevance to the proposed CTI technology described herein, thermal stability analysis was conducted under $\sim 1$ atm Ar. Fig. 7(a) shows an SEM micrograph of the opacified gel, where nano-sized titania particles were agglomerated and dispersed in the amorphous silica network. In comparison with the as-dried gel (Fig. 7(a)), no obvious morphological change was observed in $600{ }^{\circ} \mathrm{C}$ heated gel (Fig. 7(b)), implying that the microstructure was thermally stable at $600{ }^{\circ} \mathrm{C}$ in Ar for 4 h. Fig. 7(c) shows an SEM micrograph of the reinforcing YSZ fibers in the $600{ }^{\circ} \mathrm{C}$ heated gel and Fig. 7(d) shows a TEM micrograph of the incorporated mineral particles, where nano-sized titania and faceted quartz particles $(\sim 2 \mu \mathrm{m})$ were embedded in the gel matrix.

TGA results of the CTI are shown in Fig. 8 . Up to $150{ }^{\circ} \mathrm{C}$, almost no weight loss was observed while $\sim 2 \%$ weight loss appeared when heated to $400{ }^{\circ} \mathrm{C}$, which could be attributed to the removal of volatile solvent residue, e.g., methanol. After being heated at $400{ }^{\circ} \mathrm{C}$ for $4 \mathrm{~h}$, additional $\sim 2 \%$ weight loss occurred, probably due to further removal of organic residue and adsorbed water. When heated to $500{ }^{\circ} \mathrm{C}$ and held isothermally for $4 \mathrm{~h}$ in $\mathrm{Ar}$, the total weight loss of the silica gel was $\sim 6 \%$. The further weight loss was likely related to decomposition of methyl 
groups $\left(-\mathrm{CH}_{3}\right)$ into elemental carbon. The total weight loss reached $\sim 8 \%$ when heat-treated at $600{ }^{\circ} \mathrm{C}$ in $\mathrm{Ar}$ for $4 \mathrm{~h}$, indicating further carbonization of the methyl groups.

To simulate the thermal environment of a sealed TEG, both in terms of atmosphere $(\sim 1 \mathrm{~atm} \mathrm{Ar}$ and open volume) [37], the CTI was heat treated in sealed quartz ampoules where one-third of the ampoule open volume was filled with Ar and the remaining two-thirds with CTI. Figs. 9(a), (b) and (c) present the optical images of the CTI isothermally heated at $400{ }^{\circ} \mathrm{C}, 500{ }^{\circ} \mathrm{C}$, and $600{ }^{\circ} \mathrm{C}$ for $4 \mathrm{~h}$, respectively. The $400{ }^{\circ} \mathrm{C}$ heated gel discolored the least among the heated gels. FTIR spectra of the heated gels are shown in Fig. 9(d). $\mathrm{C}=\mathrm{C}$ bonding was detected in the $500{ }^{\circ} \mathrm{C}$ and $600{ }^{\circ} \mathrm{C}$ heated gels, which was consistent with the discoloration phenomenon shown in Figs. 9(b) and (c). In addition, the intensity of $\mathrm{O}-\mathrm{H}$ band increased with heating temperature, implying that the gel transitioned to a hydrophilic state due to the decomposition of methyl groups into carbon. Similarly, silica gels, made from sodium silicate precursor and MTMS silylating agent, started to lose hydrophobicity when heated to $325^{\circ} \mathrm{C}$ in air, due to the decomposition of hydrophobic $\mathrm{Si}-\mathrm{CH}_{3}$ groups into hydrophilic $\mathrm{Si}-\mathrm{OH}$ groups [12].

\subsection{Hydrophobicity}

Previously, Rao et al. have reported the characterization of superhydrophobic surfaces [13]. The same methodology was used to characterize the hydrophobic behavior of CTI. The shape of a water drop resting on a solid surface is dependent on the properties of the water drop (L), surrounding air or gas $(\mathrm{G})$ and the solid surface $(\mathrm{S})$ where it was placed $[13,38]$. This could be described by the Young's equation of the interfacial tensions at equilibrium conditions [38, 39].

$$
\gamma_{\mathrm{SG}}=\gamma_{\mathrm{SL}}+\gamma_{\mathrm{LG}} \cos \theta_{\mathrm{C}}
$$

where $\gamma_{\mathrm{SG}}, \gamma_{\mathrm{SL}}$ and $\gamma_{\mathrm{LG}}$ are the interfacial tensions between the solid and the gas or vapor, the solid and the liquid, and the liquid and the gas or vapor, respectively, and $\theta_{\mathrm{C}}$ is the equilibrium 
contact angle the liquid drop made on a smooth solid surface. Fig. 10(a) shows the water contact angle measurement of the as-dried gel. The contact angles of the as-dried, $400{ }^{\circ} \mathrm{C}, 500{ }^{\circ} \mathrm{C}$ and $600{ }^{\circ} \mathrm{C}$ heat-treated gels are $153^{\circ}, 154^{\circ}, 155^{\circ}$ and $153^{\circ}$, respectively, as shown in Figs. 10(a-d). Surfaces of the CTI were superhydrophobic with water contact angles $>150^{\circ}$. Based on these data, the CTI maintained the superhydrophobic property up to $600{ }^{\circ} \mathrm{C}$ in Ar. In addition, surface roughness seemed to play little role in hydrophobicity. Though the hydrophobic $-\mathrm{CH}_{3}$ methyl groups were supposed to be thermally unstable at temperatures $>500{ }^{\circ} \mathrm{C}[13]$, they could partially remain on the gel surface even after heating at $600{ }^{\circ} \mathrm{C}$ for $4 \mathrm{~h}$ in Ar. This could explain the superhydrophobicity of the $600{ }^{\circ} \mathrm{C}$ heated gel. However, re-entrant surface curvature, in conjunction with chemical composition, could be another possible explanation of the superhydrophobic surfaces of the heat-treated gel [39]. To elucidate this phenomenon, the gel was heated isothermally at $800{ }^{\circ} \mathrm{C}$ and $1000{ }^{\circ} \mathrm{C}$ in $\mathrm{Ar}$ for $4 \mathrm{~h}$, respectively. As shown in Figs. 10(e) and (f), the gels became completely hydrophilic. Since no obvious change in the gel microstructure was observed, it could be concluded that the remaining of hydrophobic methyl groups $\left(\mathrm{CH}_{3}\right)$ rather than surface re-entrant angle was the main reason for the superhydrophobicity of the $600{ }^{\circ} \mathrm{C}$ heated gel. In comparison, surface-modified ambiently-dried silica aerogels reported by Rao. et al also exhibited superhydrophobicity with water contact angle $>150^{\circ}$ and retained the hydrophobicity up to $450{ }^{\circ} \mathrm{C}$ in $\mathrm{N}_{2}$ atmosphere [12].

\subsection{Electrical conductivity}

Currently, $\mathrm{Bi}_{2} \mathrm{Te}_{3}$-based alloys are the only commercially available thermoelectric materials with a hot side temperature limit of $250{ }^{\circ} \mathrm{C}$ [40]. To achieve higher temperature capability, n-type skutterudite (nominal composition: $\mathrm{Yb}_{0.09} \mathrm{Ba}_{0.05} \mathrm{La}_{0.05} \mathrm{Co}_{4} \mathrm{Sb}_{12}$ ) and p-type skutterudite (nominal composition: $\mathrm{Mm}_{0.30} \mathrm{Fe}_{1.46} \mathrm{Co}_{2.54} \mathrm{Sb}_{12.05}$; $\mathrm{Mm}$ : Mischmetal alloy of $\mathrm{La}, \mathrm{Ce}, \mathrm{Pr}$ and $\mathrm{Nd}$ ) were 
considered because these materials showed adequate thermoelectric and mechanical performance $[41,42]$. Here, n-type and p-type skutterudite legs were cast around by opacified CTI as shown in Fig. 11(a), where the electrical resistance of CTI was measured by a multimeter. The electrical resistance within each skutterudite thermoelectric leg was about several ohms. In contrast, the electrical resistance between the skutterudite electrodes was $>1 \mathrm{G} \Omega$. After heating at $400{ }^{\circ} \mathrm{C}$, $500{ }^{\circ} \mathrm{C}$ and $600{ }^{\circ} \mathrm{C}$ for $4 \mathrm{~h}$ in Ar, respectively, the electrical resistance between the skutterudite electrodes was still $>1 \mathrm{G} \Omega$, though the formation of carbon (as evident by the discoloration) was expected to reduce the electrical resistance. Fig. 11(b) presents the EIS spectra of the heated gels. EIS was conducted in conjunction with the DC measurement to determine if the gel surface adsorbed conductive protons, which could be present after each heat treatment. In general, the gel samples, before and after heat treatment, exhibited capacitive behavior, indicating high electrical resistance, which was in agreement with the DC multimeter measurement. Thus, the room temperature electrical conductivity of the heat-treated CTI was negligible and not likely to cause short-circuiting between thermoelectric elements and other electrical hardware.

\subsection{Compression test}

The mechanical properties of CTI before and after heat treatment were characterized by compression test. Fig. 12(a) shows the stress-strain behavior of CTI under compression. The opacified CTI yielded at approximately $10 \%$ strain with no noticeable macroscopic crack formation. Rupture occurred at $12 \%$ strain where macroscopic cracks were clearly visible and propagated through the gel specimen. No sudden collapse occurred at any stage of the compression test. The Young's modulus of the opacified gel was $3.7 \mathrm{MPa}$, as determined using the slope of the elastic deformation line of the strain-stress curve in Fig. 12(c). In contrast, the $500{ }^{\circ} \mathrm{C}$ heated gel yielded at 4.5\% strain (Fig. 12(b)) and exhibited a higher Young's modulus 
( 8.4 MPa), more rigid than the as-dried gel. The increase of Young's modulus was likely a result of sintering between constituents and perhaps a slight reduction in porosity after heat treatment [19]. Shear cracks were also more pronounced in the heated gel compared to the asdried gel, indicating a reduction in fracture toughness, though this is difficult to quantify. In comparison with the supercritically-dried MTMS-derived silica gels (Young's modulus $<0.15$ MPa), the CTI exhibited a much higher Young's modulus (measured by uniaxial compression test) $[20,43]$.

\subsection{Thermal conductivity measurement}

The thermal conductivity (measured at room temperature) of the CTI as a function of heat treatment temperature is shown in Fig. 13. Initially, the thermal conductivity of as-dried gel was $\sim 0.076 \mathrm{~W} /(\mathrm{m} . \mathrm{K})$, followed by a slight increase to $\sim 0.080 \mathrm{~W} /\left(\mathrm{m} . \mathrm{K}\right.$ ) (after being heated at $300{ }^{\circ} \mathrm{C}$ in Ar for $4 \mathrm{~h}$ ) before decreasing to $\sim 0.075 \mathrm{~W} /(\mathrm{m} . \mathrm{K})\left(500{ }^{\circ} \mathrm{C}\right.$ heated $\left.\mathrm{CTI}\right)$. The thermal conductivity of the gel slightly increased to $\sim 0.079 \mathrm{~W} /(\mathrm{m} . \mathrm{K})$ after being heated at $600{ }^{\circ} \mathrm{C}$ in $\mathrm{Ar}$ for $4 \mathrm{~h}$. The small variation of the thermal conductivity could have been caused by water adsorption and carbonization of methyl groups of the heated gels, since water and carbon both exhibit higher thermal conductivities than porous silica gels [7]. Generally, the room temperature thermal conductivity of the gel was $<0.08 \mathrm{~W} /(\mathrm{m} . \mathrm{K})$, lower than the reported value of a MTMSderived silica gel, $\sim 0.086-0.109 \mathrm{~W} /(\mathrm{m} . \mathrm{K})[13]$. The discrepancy could be attributed to the fillers in this study or measurement methods or actual sample volumes being tested. For typical thermal conductivity measurements, uncertainty of $\pm 10 \%$ is reasonable. Although the thermal conductivity was higher than a typical supercritically-dried silica aerogel insulation (in the order of $0.02 \mathrm{~W} /(\mathrm{m} . \mathrm{K}))[8,44]$, it was still low enough to reduce parasitic heat loss in TEG technology as previously demonstrated [40]. 


\section{Conclusions}

A combination of sol-gel chemistry and composite material engineering was used to develop a cast-in-place, high temperature thermal insulation (CTI). To enable ambient drying, a unique silica microstructure was made using MTMS as a precursor. To further reduce shrinkage associated with solvent evaporation, zirconia fibers (YSZ) were integrated and the volumetric shrinkage was less than 5\%. The gel mainly consisted of amorphous $\mathrm{SiO}_{2}$, showing high castability, machinability, and thermal stability. It was thermally stable and maintained superhydrophobicity (with water contact angle $>150^{\circ}$ ) at $600{ }^{\circ} \mathrm{C}$ in Ar. The gel showed negligible electrical conductivity with an electrical resistance $>1 \mathrm{G}$ ohms before and after heat treatment. It also demonstrated high stiffness with a Young's modulus $\sim 3.7 \mathrm{MPa}$ and showed no cracking up to $10 \%$ strain at room temperature in the as-cast form. In addition, regardless of heat treatment temperature (up to $600{ }^{\circ} \mathrm{C}$ in $\mathrm{Ar}$ ), the thermal conductivity of the gel at room temperature was $<0.08 \mathrm{~W} /(\mathrm{m} . \mathrm{K})$. Collectively, these data indicate that the ambiently-dried silica gel is a promising candidate for use as thermal insulation in thermoelectric generators and numerous other technologies requiring improved thermal efficiency and management.

\section{Reference}

[1] P.C. Stern, K.B. Janda, M.A. Brown, L. Steg, E.L. Vine, L. Lutzenhiser. Opportunities and insights for reducing fossil fuel consumption by households and organizations, Nature Energy 1 (2016) 16043. 
[2] Energy flow chart, Lawrence Livermore National Laboratory and the Department of Energy. March, 2016.

[3] L.E. Bell. Cooling, heating, generating power, and recovering waste heat with thermoelectric systems, Science 321 (2008) 1457-1461.

[4] K.M. Saqr, M.K. Mansour, M. Musa. Thermal design of automobile exhaust based thermoelectric generators: Objectives and challenges, International Journal of Automotive Technology 9 (2008) 155-160.

[5] S.M. Jones, J. Sakamoto. Applications of aerogels in space exploration. Aerogels Handbook. Springer, 2011. pp. 721-746.

[6] S. Kistler. Coherent expanded-aerogels, The Journal of Physical Chemistry 36 (1932) 5264.

[7] J. Fricke, T. Tillotson. Aerogels: production, characterization, and applications, Thin Solid Films 297 (1997) 212-223.

[8] A.S. Dorcheh, M. Abbasi. Silica aerogel; synthesis, properties and characterization, Journal of materials processing technology 199 (2008) 10-26.

[9] L.W. Hrubesh. Aerogel applications, Journal of Non-Crystalline Solids 225 (1998) 335342.

[10] A.M. Anderson, M.K. Carroll. Hydrophobic silica aerogels: review of synthesis, properties and applications. Aerogels Handbook. Springer, 2011. pp. 47-77.

[11] M. Schneider, A. Baiker. High-surface-area titania aerogels: preparation and structural properties, Journal of Materials Chemistry 2 (1992) 587-589.

[12] A.P. Rao, A.V. Rao, G.M. Pajonk. Hydrophobic and physical properties of the ambient pressure dried silica aerogels with sodium silicate precursor using various surface modification agents, Applied Surface Science 253 (2007) 6032-6040.

[13] A.V. Rao, M.M. Kulkarni, D. Amalnerkar, T. Seth. Superhydrophobic silica aerogels based on methyltrimethoxysilane precursor, Journal of Non-Crystalline Solids 330 (2003) 187195. 
[14] F. Schwertfeger, D. Frank, M. Schmidt. Hydrophobic waterglass based aerogels without solvent exchange or supercritical drying, Journal of Non-Crystalline Solids 225 (1998) 24-29.

[15] R. Deshpande, D.M. Smith, C.J. Brinker. Preparation of high porosity xerogels by chemical surface modification, (1996), US5565142 A.

[16] S. Hæreid, J. Anderson, M. Einarsrud, D. Hua, D. Smith. Thermal and temporal aging of TMOS-based aerogel precursors in water, Journal of non-crystalline solids 185 (1995) 221-226.

[17] L.A. Capadona, M.A.B. Meador, A. Alunni, E.F. Fabrizio, P. Vassilaras, N. Leventis. Flexible, low-density polymer crosslinked silica aerogels, Polymer 47 (2006) 5754-5761.

[18] N. Leventis, C. Sotiriou-Leventis, G. Zhang, A.-M.M. Rawashdeh. Nanoengineering strong silica aerogels, Nano letters 2 (2002) 957-960.

[19] J. Sakamoto, R.P. Maloney, T. Thompson. Porous sol gels and methods and structures related thereto, (2012), US 2014/0170350 A1.

[20] N.D. Hegde, A. Venkateswara Rao. Physical properties of methyltrimethoxysilane based elastic silica aerogels prepared by the two-stage sol-gel process, Journal of Materials Science 42 (2007) 6965-6971.

[21] S.D. Bhagat, C.-S. Oh, Y.-H. Kim, Y.-S. Ahn, J.-G. Yeo. Methyltrimethoxysilane based monolithic silica aerogels via ambient pressure drying, Microporous and Mesoporous Materials 100 (2007) 350-355.

[22] J. Kuhn, T. Gleissner, M. Arduini-Schuster, S. Korder, J. Fricke. Integration of mineral powders into $\mathrm{SiO}_{2}$ aerogels, Journal of Non-Crystalline Solids 186 (1995) 291-295.

[23] J. Sakamoto, G. Snyder, T. Calliat, J.-P. Fleurial, S. Jones, J.-A. Palk. System and method for fabrication of high-efficiency durable thermoelectric devices, (2005), US 2006/0157101 A1.

[24] M.A. Aegerter, N. Leventis, M.M. Koebel. Aerogels handbook, Springer Science \& Business Media, 2011.

[25] S.E. Gustafsson. Transient plane source techniques for thermal conductivity and thermal diffusivity measurements of solid materials, Review of scientific instruments 62 (1991) 797-804.

[26] P.C. Hiemenz, R. Rajagopalan. Principles of Colloid and Surface Chemistry, revised and expanded, CRC press, 1997. 
[27] L.T. Canham, A. Cullis, C. Pickering, O. Dosser, T. Cox, T. Lynch. Luminescent anodized silicon aerocrystal networks prepared by supercritical drying, Nature 368 (1994) 133135.

[28] Q. Tang, T. Wang. Preparation of silica aerogel from rice hull ash by supercritical carbon dioxide drying, The Journal of supercritical fluids 35 (2005) 91-94.

[29] Z. Deng, J. Wang, A. Wu, J. Shen, B. Zhou. High strength SiO2 aerogel insulation1, Journal of Non-Crystalline Solids 225 (1998) 101-104.

[30] M.A. Worsley, P.J. Pauzauskie, S.O. Kucheyev, J.M. Zaug, A.V. Hamza, J.H. Satcher, T.F. Baumann. Properties of single-walled carbon nanotube-based aerogels as a function of nanotube loading, Acta Materialia 57 (2009) 5131-5136.

[31] V. Dueik, M. Moreno, P. Bouchon. Microstructural approach to understand oil absorption during vacuum and atmospheric frying, Journal of Food Engineering 111 (2012) 528-536.

[32] A.P. Rao, A.V. Rao, G. Pajonk. Hydrophobic and physical properties of the two step processed ambient pressure dried silica aerogels with various exchanging solvents, Journal of sol-gel science and technology 36 (2005) 285-292.

[33] A.P. Rao, A.V. Rao. Microstructural and physical properties of the ambient pressure dried hydrophobic silica aerogels with various solvent mixtures, Journal of Non-Crystalline Solids 354 (2008) 10-18.

[34] J.-A. Paik, J. Sakamoto, S. Jones. Aerogel/Particle Composites for Thermoelectric Devices, (2006).

[35] S. Musić, N. Filipović-Vinceković, L. Sekovanić. Precipitation of amorphous SiO2 particles and their properties, Brazilian Journal of Chemical Engineering 28 (2011) 89-94.

[36] H.C. Beachell, B. Katlafsky. Vibrational spectrum of dimethylphosphine, The Journal of Chemical Physics 27 (1957) 182-185.

[37] J.R. Salvador. Cost-competitive Advanced Thermoelectric Generators for Direct Conversion of Vehicle Waste Heat into Useful Electric Power, (2014), 2014 DOE Hydrogen and Fuel Cells Program and Vehicle Technologies Office Annual Merit Review and Peer Evaluation Meeting 
[38] R. Tadmor. Line energy and the relation between advancing, receding, and young contact angles, Langmuir 20 (2004) 7659-7664.

[39] A. Tuteja, W. Choi, M. Ma, J.M. Mabry, S.A. Mazzella, G.C. Rutledge, G.H. McKinley, R.E. Cohen. Designing superoleophobic surfaces, Science 318 (2007) 1618-1622.

[40] J.R. Salvador, J.Y. Cho, Z. Ye, J.E. Moczygemba, A.J. Thompson, J.W. Sharp, J.D. Koenig, R. Maloney, T. Thompson, J. Sakamoto, H. Wang, A.A. Wereszczak. Conversion efficiency of skutterudite-based thermoelectric modules, Physical Chemistry Chemical Physics 16 (2014) $12510-12520$.

[41] J.R. Salvador, J. Yang, A.A. Wereszczak, H. Wang, J.Y. Cho. Temperature Dependent Tensile Fracture Stress of $\mathrm{n}$ - and p-Type Filled-Skutterudite Materials, Science of Advanced Materials 3 (2011) 577-586.

[42] J.R. Salvador, J.Y. Cho, Z. Ye, J.E. Moczygemba, A.J. Thompson, J.W. Sharp, J.D. König, R. Maloney, T. Thompson, J. Sakamoto. Thermal to electrical energy conversion of skutterudite-based thermoelectric modules, Journal of electronic materials 42 (2013) 1389-1399.

[43] A.V. Rao, S.D. Bhagat, H. Hirashima, G. Pajonk. Synthesis of flexible silica aerogels using methyltrimethoxysilane (MTMS) precursor, Journal of colloid and interface science 300 (2006) 279-285.

[44] S.S. Kistler. The Relation between Heat Conductivity and Structure in Silica Aerogel, The Journal of Physical Chemistry 39 (1934) 79-86. 


\section{Acknowledgements}

This work was supported by General Motors (GM) and the US Department of Energy (DOE) under the award DE-EE0005432. The work performed at Oak Ridge National Laboratory (ORNL) was under a Work for Other (WFO) contract with GM. ORNL is managed by UT Battelle LLC for DOE under Contract No. DE-AC05000OR22725. Eric Jianfeng Cheng thanks Zeta Tak For $\mathrm{Yu}$ and Trenton Wilke for their technical help in contact angle imaging and TGA test in this study. 


\section{Figure captions}

Fig. 1 3D Illustrations of MTMS-derived silica network (a) pearl-necklace structure of silica gel, (b) heat transfer mechanisms in $\mathrm{TiO}_{2}$ opacified silica gel.

Fig. 2 Gel casting and gelation in a 20 ml glass vial (a) initial mixture solution, (b) as gelation occurred, the solution viscosity increased and became opaque in approximately 8 min, and (c) the sol transformed into a rigid monolith in $\sim 20 \mathrm{~min}$.

Fig. 3 SEM micrographs of as-dried gels at various magnifications. Dashed circles highlight micron-sized pores in (a) and (d).

Fig. 4 Mass loss and diameter shrinkage of cylindrical gels (after aging process) as a function of drying time (a) without mineral fillers and (b) with mineral fillers.

Fig. 5 Optical images of opacified gels cast into different forms (a) a rod cast in a polyethylene tube, (b) a cylinder rod with high aspect ratio, (c) a complex macroscopic molded gel, (d) a gel cut into a cube demonstrating machinability

Fig. 6 XRD patterns and Raman spectra of as-dried gels and the mineral fillers (a) XRD patterns of opacified and unopacified gels, (b) Raman spectra of an as-dried gel (with fillers) and the mineral fillers

Fig. 7 Electron micrographs of opacified gels and the mineral fillers before and after heat treatment (a) SEM micrograph of as-dried gel, (b) SEM micrograph of $600{ }^{\circ} \mathrm{C}$ heated gel, (c) SEM micrograph of zirconia fibers in a $600{ }^{\circ} \mathrm{C}$ heated gel and (d) TEM micrograph of nanosized titania and micron-sized quartz particles embedded in the gel matrix. 
Fig. 8 TGA results of gels heated at $400{ }^{\circ} \mathrm{C}, 500{ }^{\circ} \mathrm{C}$ and $600{ }^{\circ} \mathrm{C}$ in Ar for $4 \mathrm{~h}$, respectively

Fig. 9 Optical images of gels heated in Ar-filled quartz ampoules and FTIR analysis of the heated gels (a) optical image of $400{ }^{\circ} \mathrm{C}$ heated gel, (b) $500{ }^{\circ} \mathrm{C}$ heated gel, (c) $600{ }^{\circ} \mathrm{C}$ heated gel, and (d) FTIR (in Attenuated Total Reflection mode) spectra of the heated gels.

Fig. 10 Water contact angle measurement of heated gels (a) as-dried gel, (b) $400{ }^{\circ} \mathrm{C}$ heated gel (c) $500{ }^{\circ} \mathrm{C}$ heated gel, (d) $600{ }^{\circ} \mathrm{C}$ heated gel, (e) $800{ }^{\circ} \mathrm{C}$ heated gel, and (f) $1000{ }^{\circ} \mathrm{C}$ heated gel

Fig. 11 Electrical resistance measurement of gels before and after heat treatment (a) electrical resistance measurement of as-dried gel between skutterudite electrodes using a multimeter, (b) EIS spectra of gels before and after heat treatment.

Fig. 12 Compression tests of as-dried and heat-treated gels (a) compression behavior of asdried gel (optical images), (b) compression of $500{ }^{\circ} \mathrm{C}$ heated gel and (c) stress-strain curves of as-dried and $500{ }^{\circ} \mathrm{C}$ heated gels

Fig. 13 Thermal conductivity measurement of CTI Thermal conductivity (room temperature) of gels as a function of heat treatment temperature. 


\section{Graphical Abstract}

A cast-in-place, ambiently-dried, silica-based thermal insulation was synthesized using methyltrimethoxysilane (MTMS) as the precursor. To allow for casting into and around small, orthogonal features, zirconia fibers were added to increase stiffness and minimize contraction that could otherwise cause cracking during drying. Nano-sized titania powder was incorporated as an opacifier to reduce radiative heat transport. The insulation showed a pearl necklace-like microstructure that was mechanically robust with a Young's modulus $\sim 3.7 \mathrm{MPa}$. Macroporous pores ranging from 3 to $30 \mu \mathrm{m}$ penetrated the silica gel network. The gel retained its superhydrophobicity, high electrical resistance (> $1 \mathrm{G} \mathrm{ohm})$ and low thermal conductivity $(\sim 0.08$ $\mathrm{W} /(\mathrm{m} . \mathrm{K})$ ) after heating at $600{ }^{\circ} \mathrm{C}$ in Ar for $4 \mathrm{~h}$. We believe this technology can act as an effective cast-in-place thermal insulation (CTI) for thermoelectric generator applications.

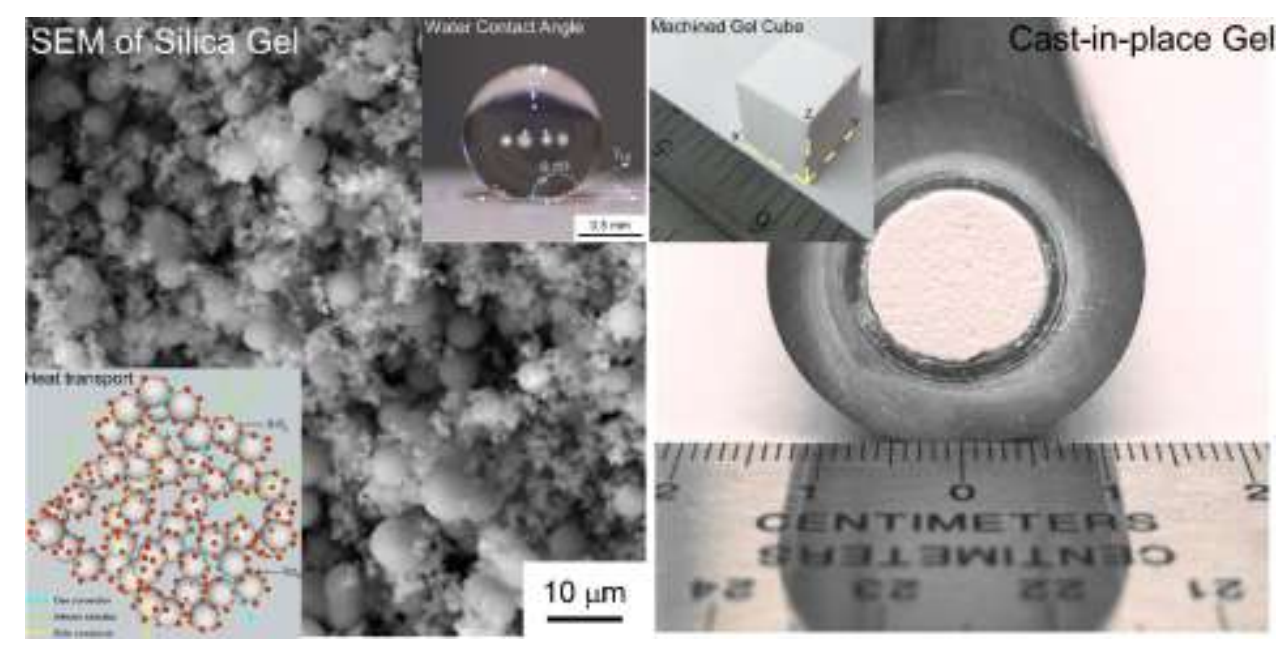



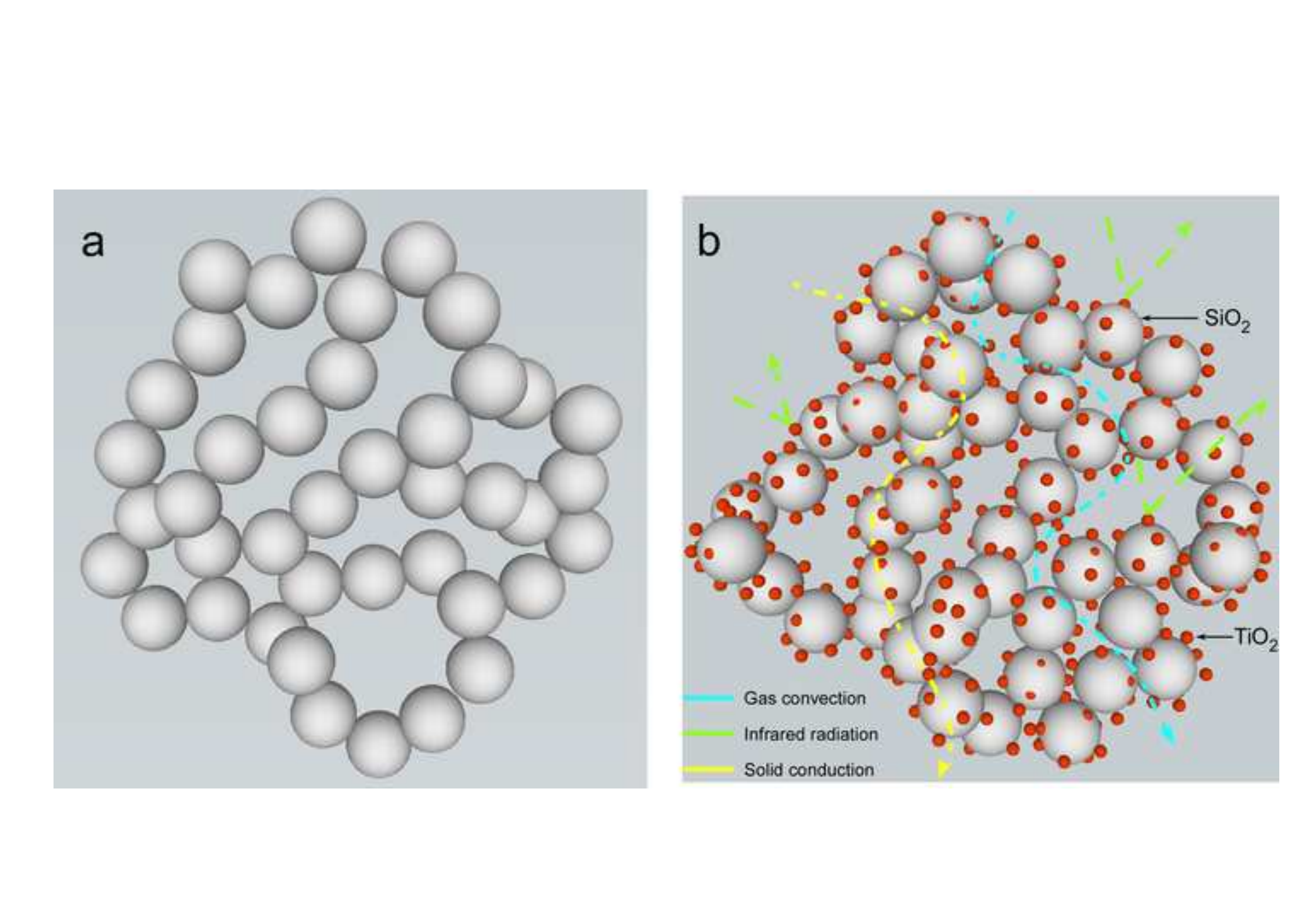

.
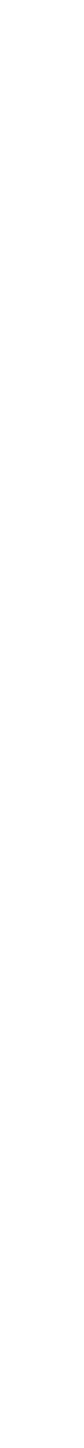

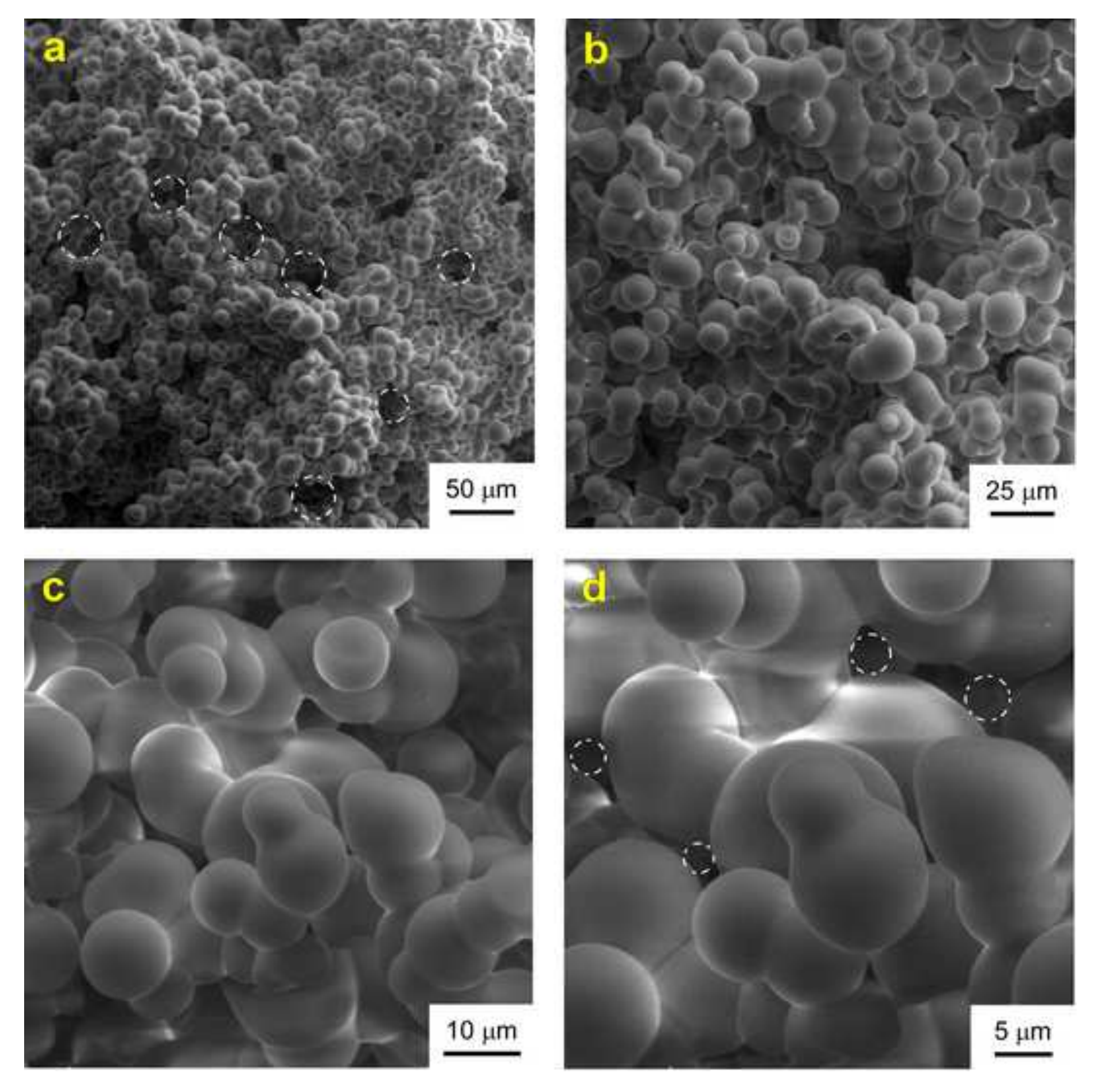

Figure 3

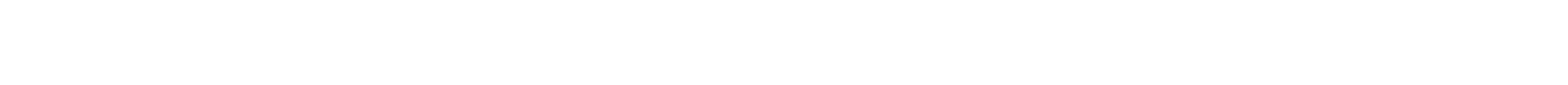
.

$$
\text { . }
$$



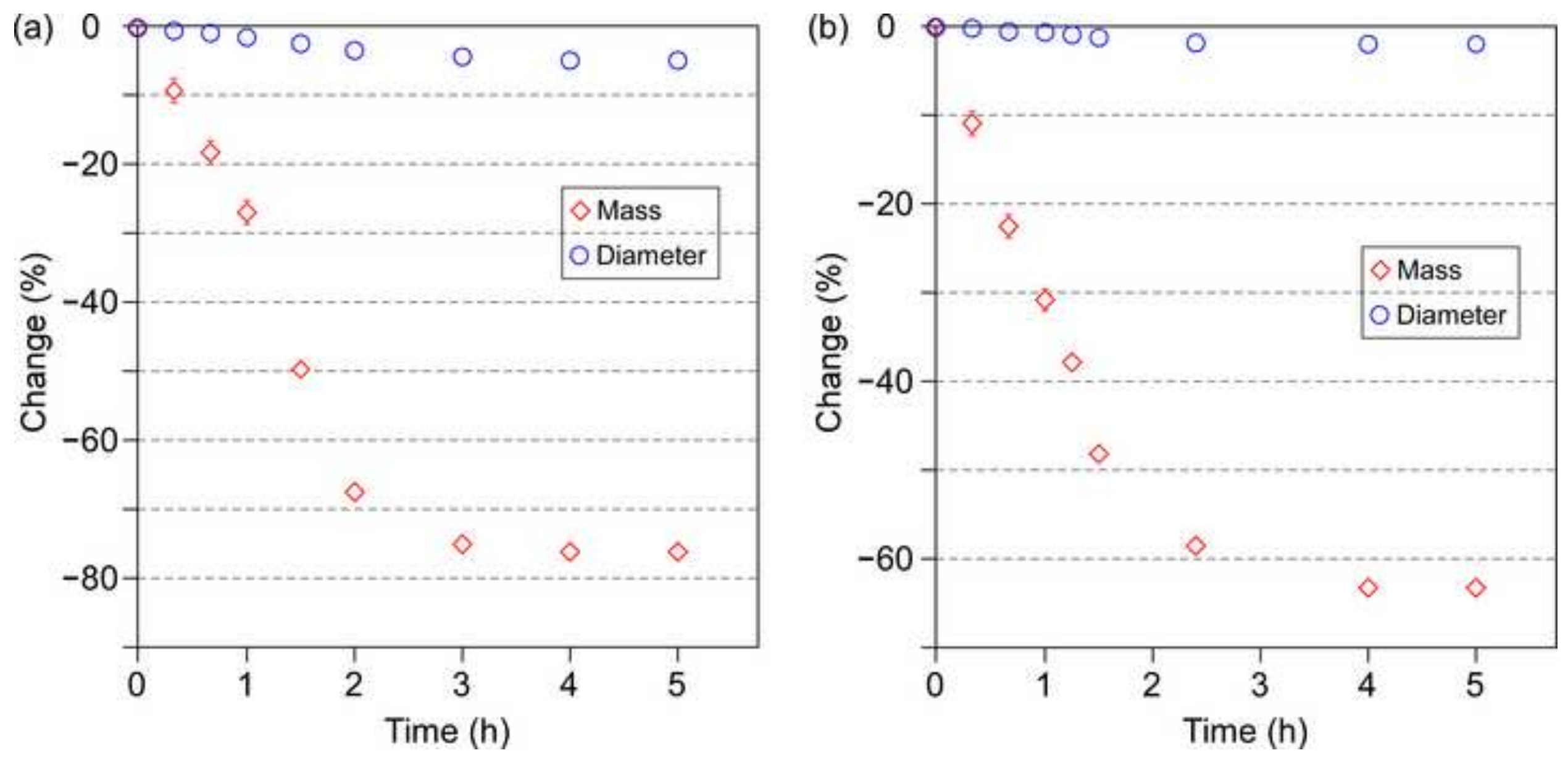

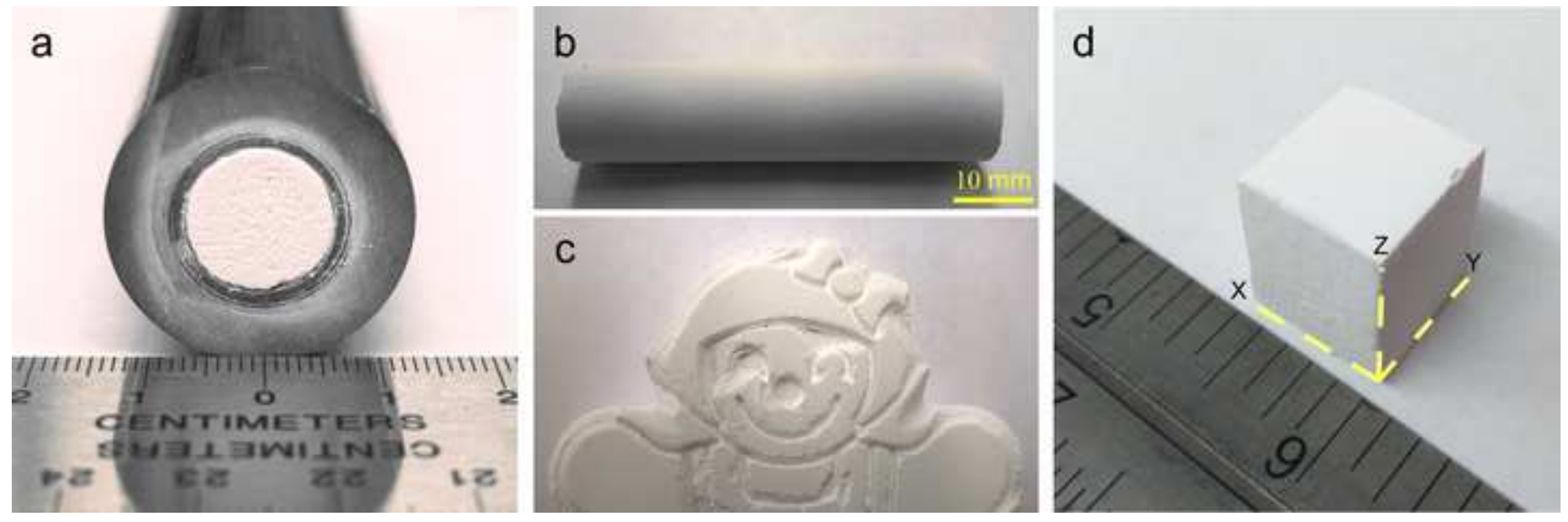

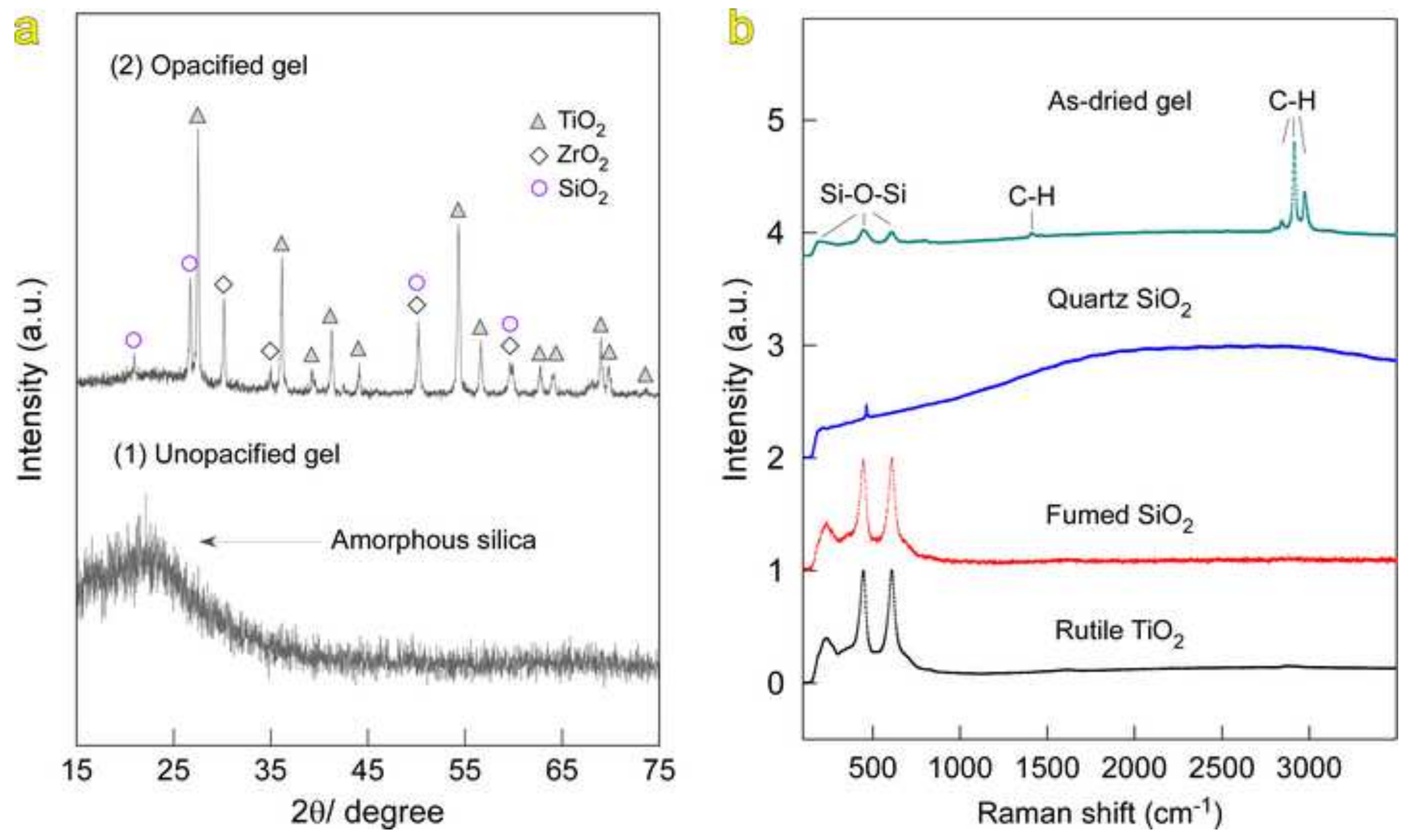

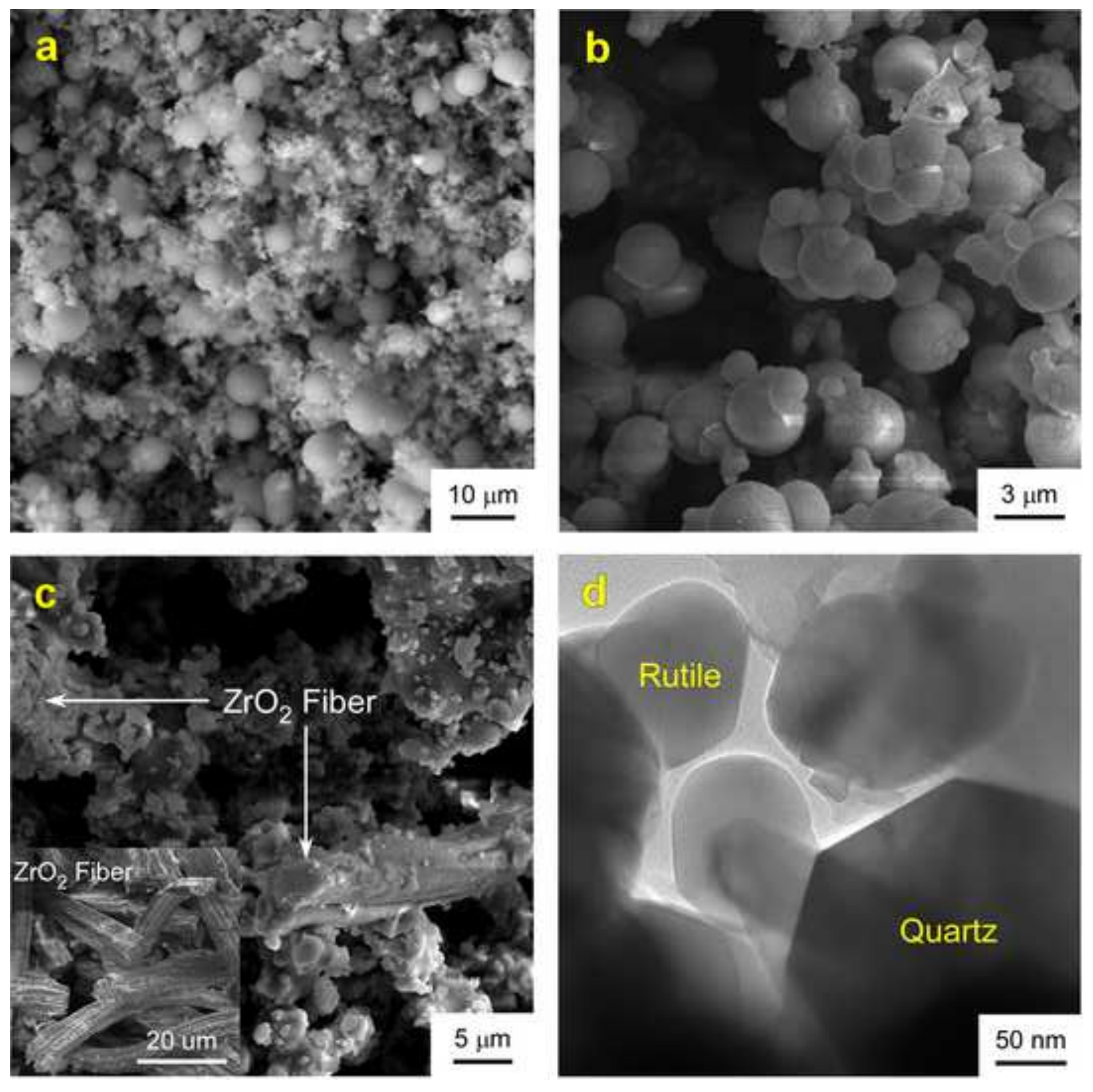


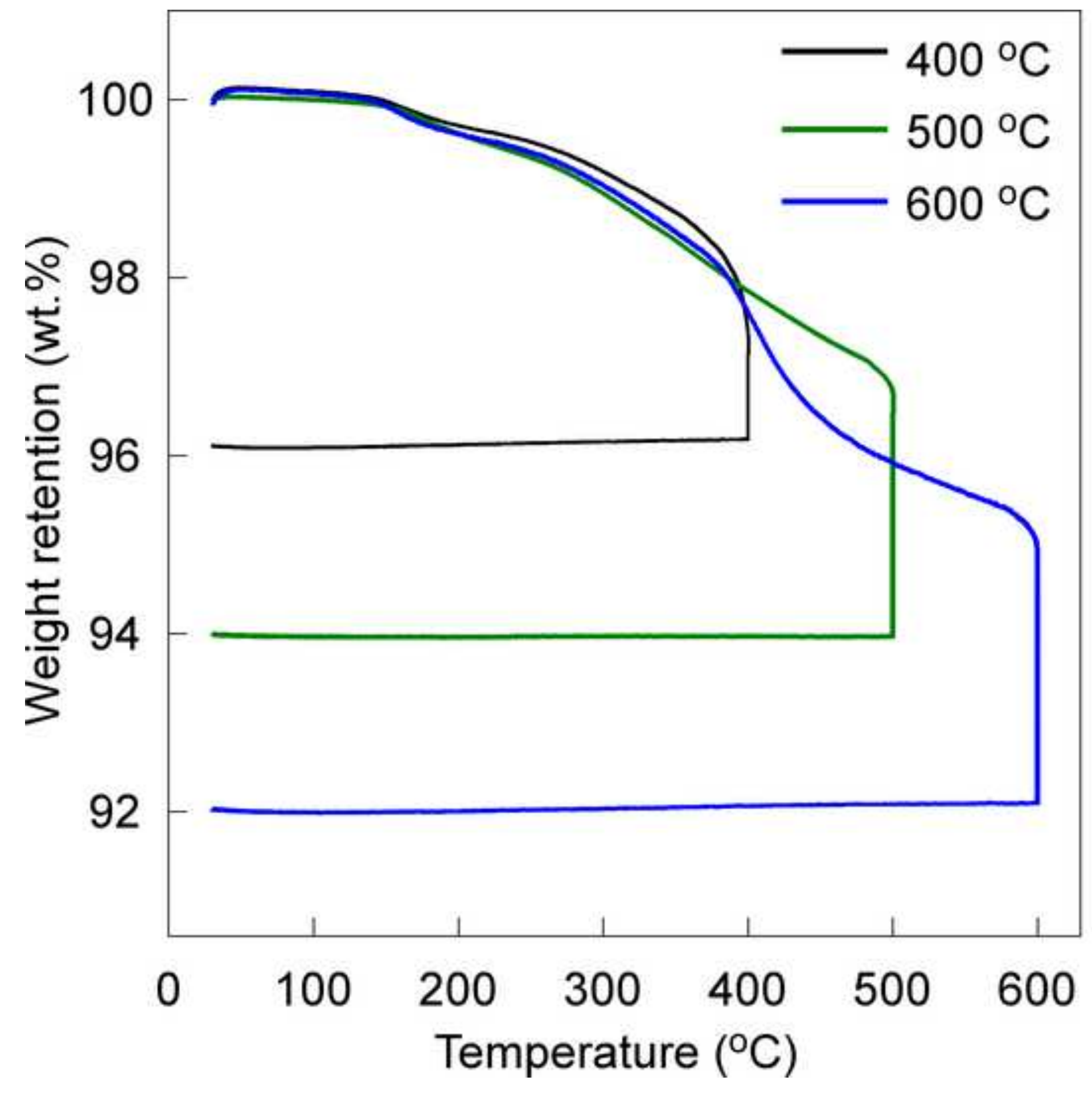



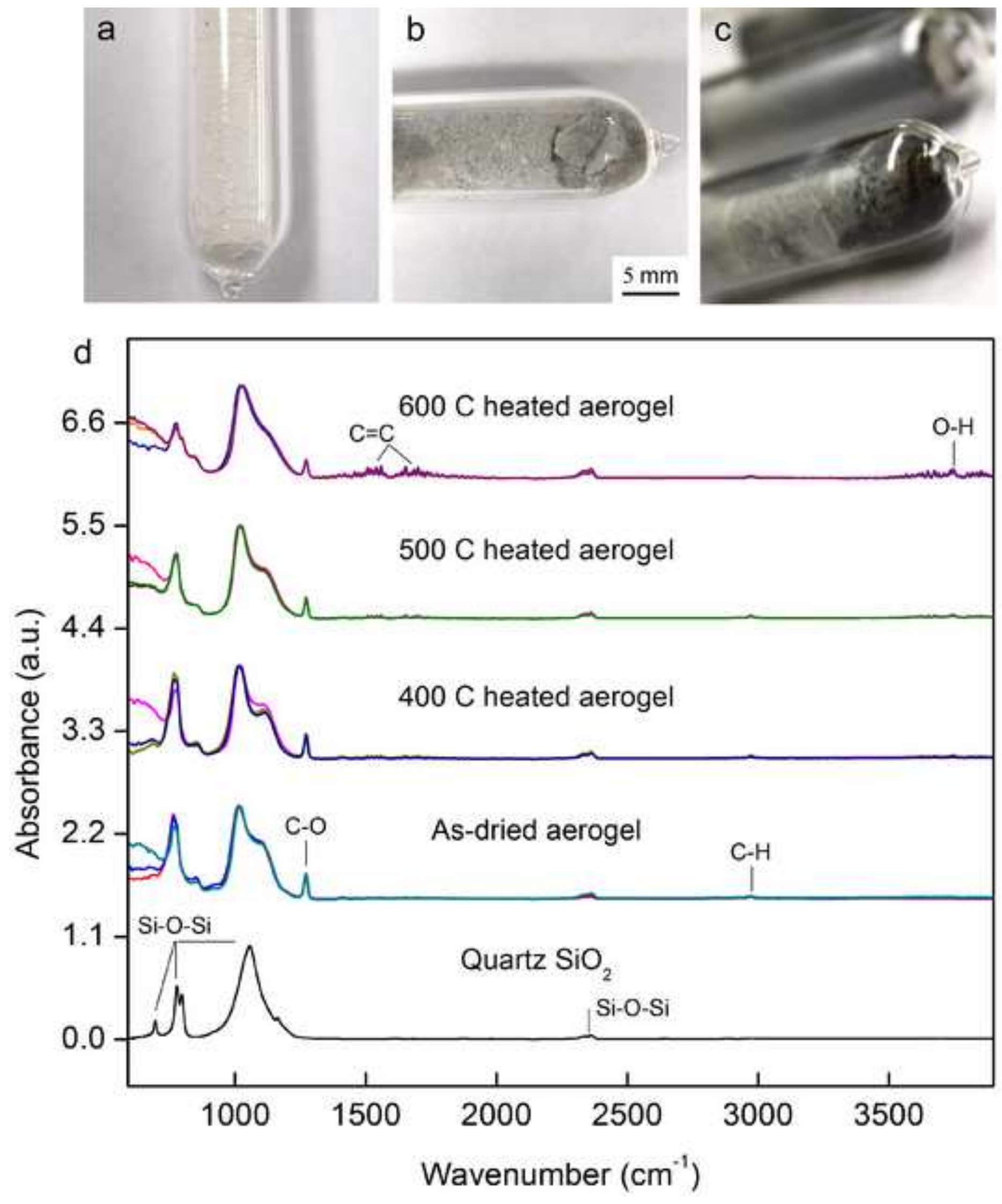

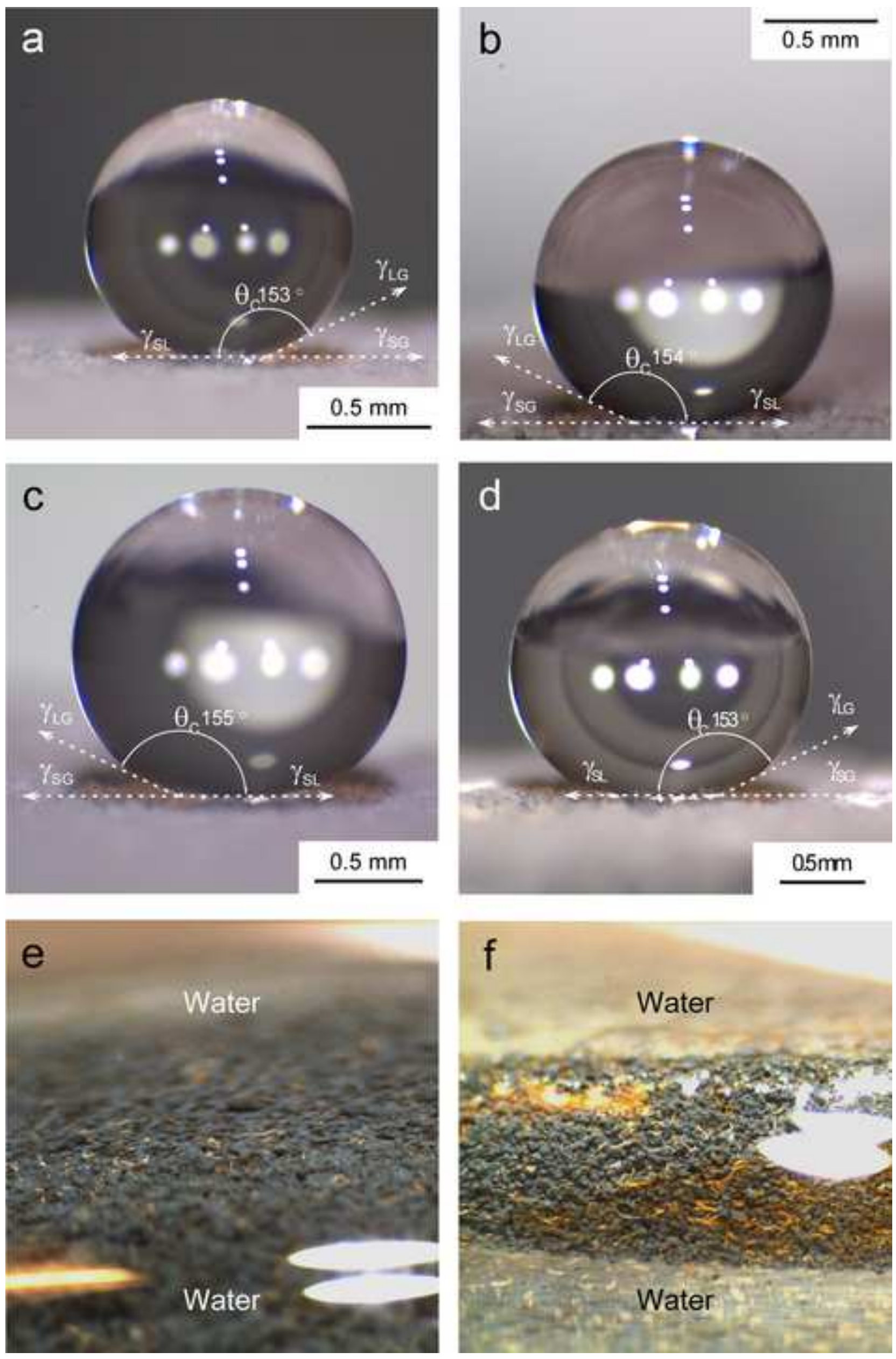

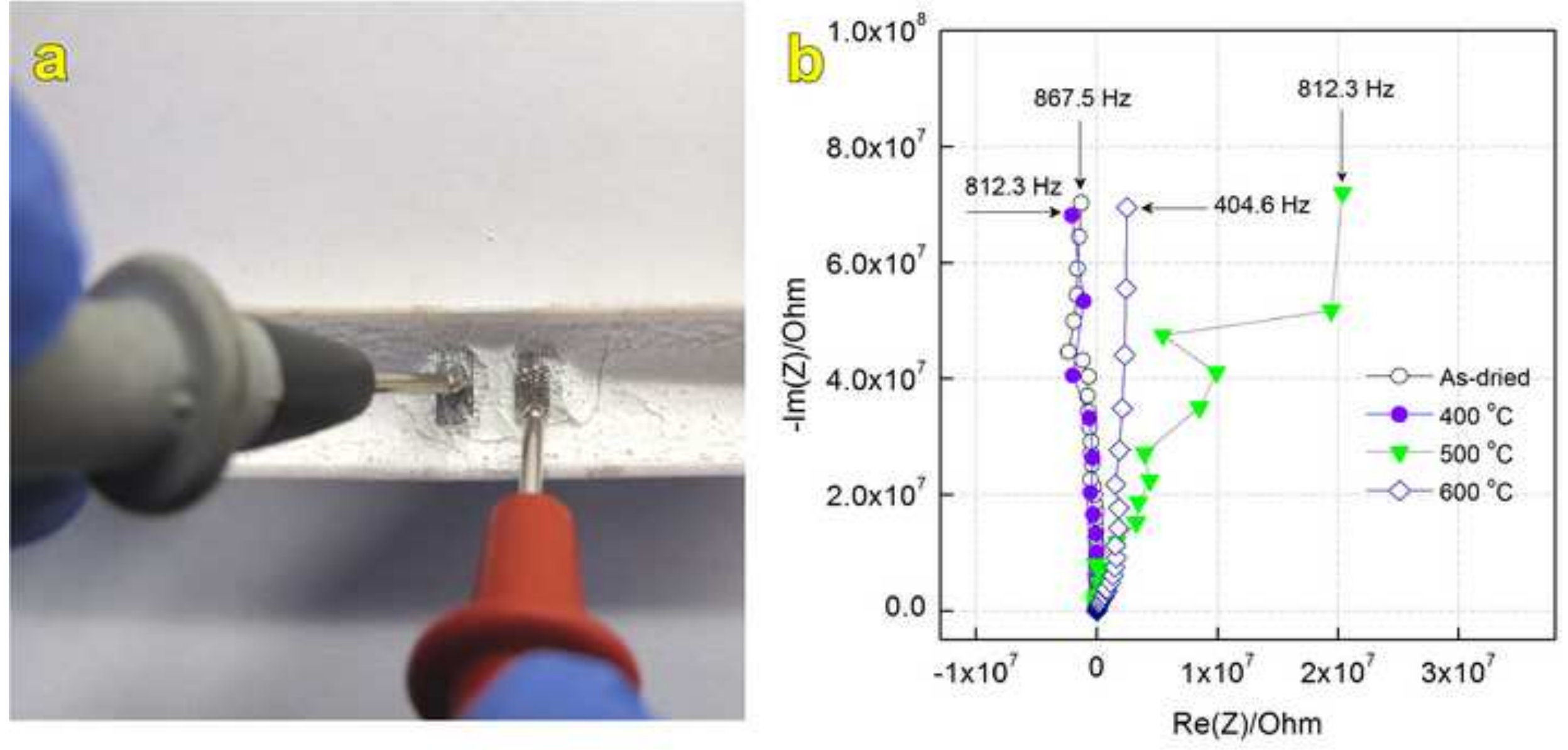
a
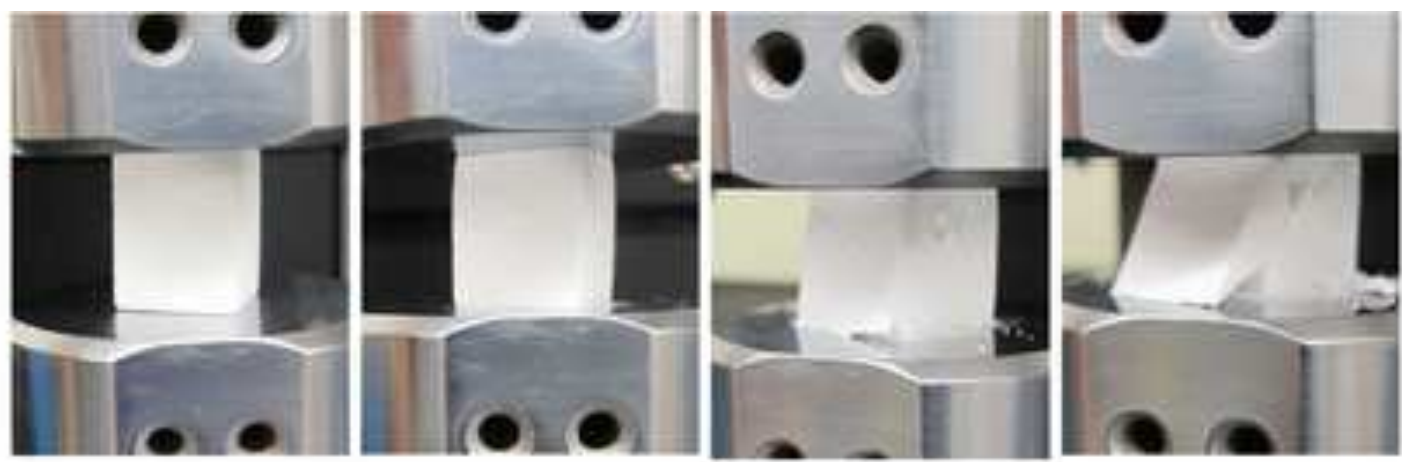

Strain: $1.5 \%$

Strain: $10 \%$, yield

Strain: $20 \%$

Strain: $30 \%$

b

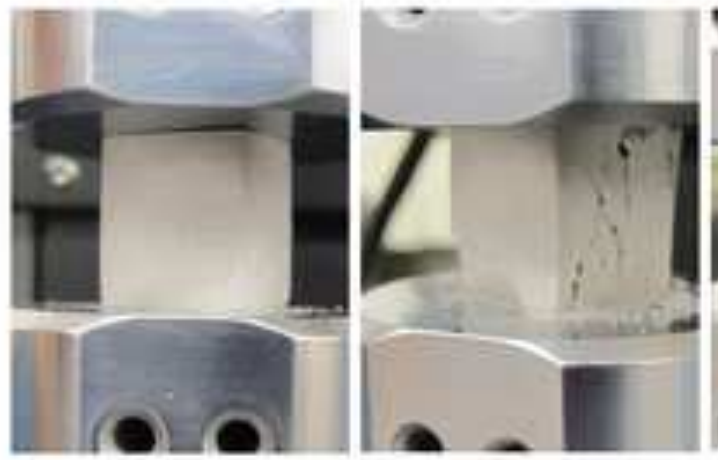

Strain: $4.5 \%$, yield Strain: $10 \%$

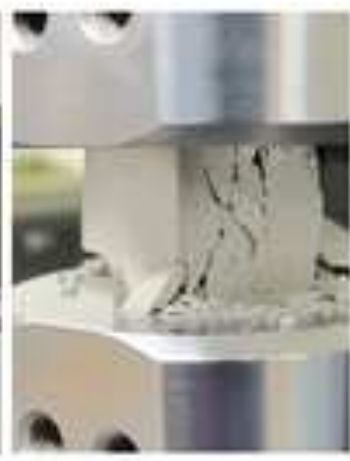

Strain: $20 \%$

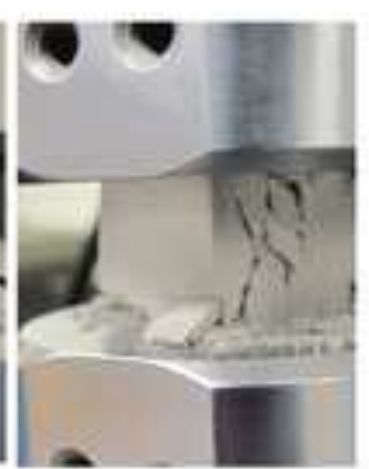

Strain: $25 \%$

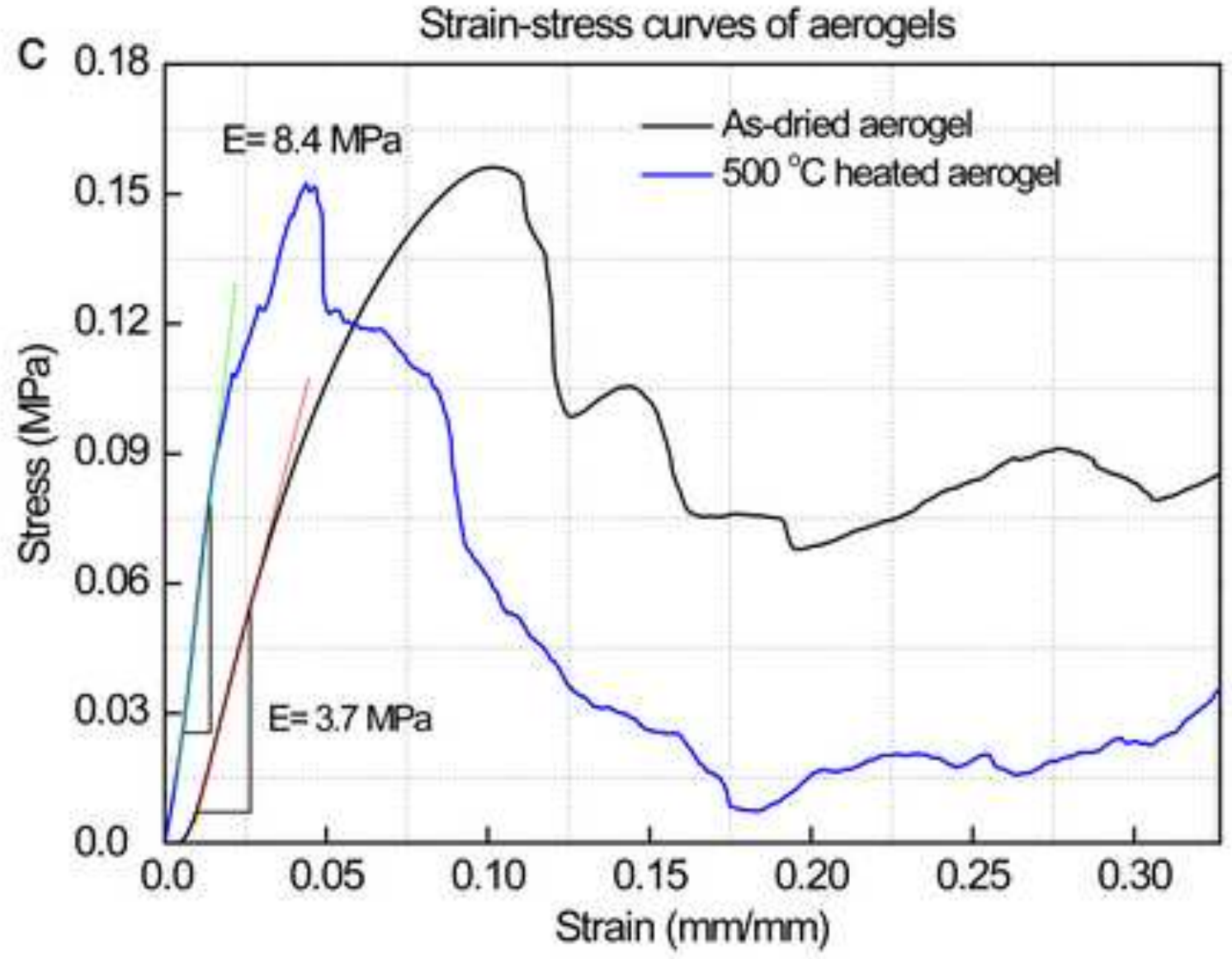


Figure 13

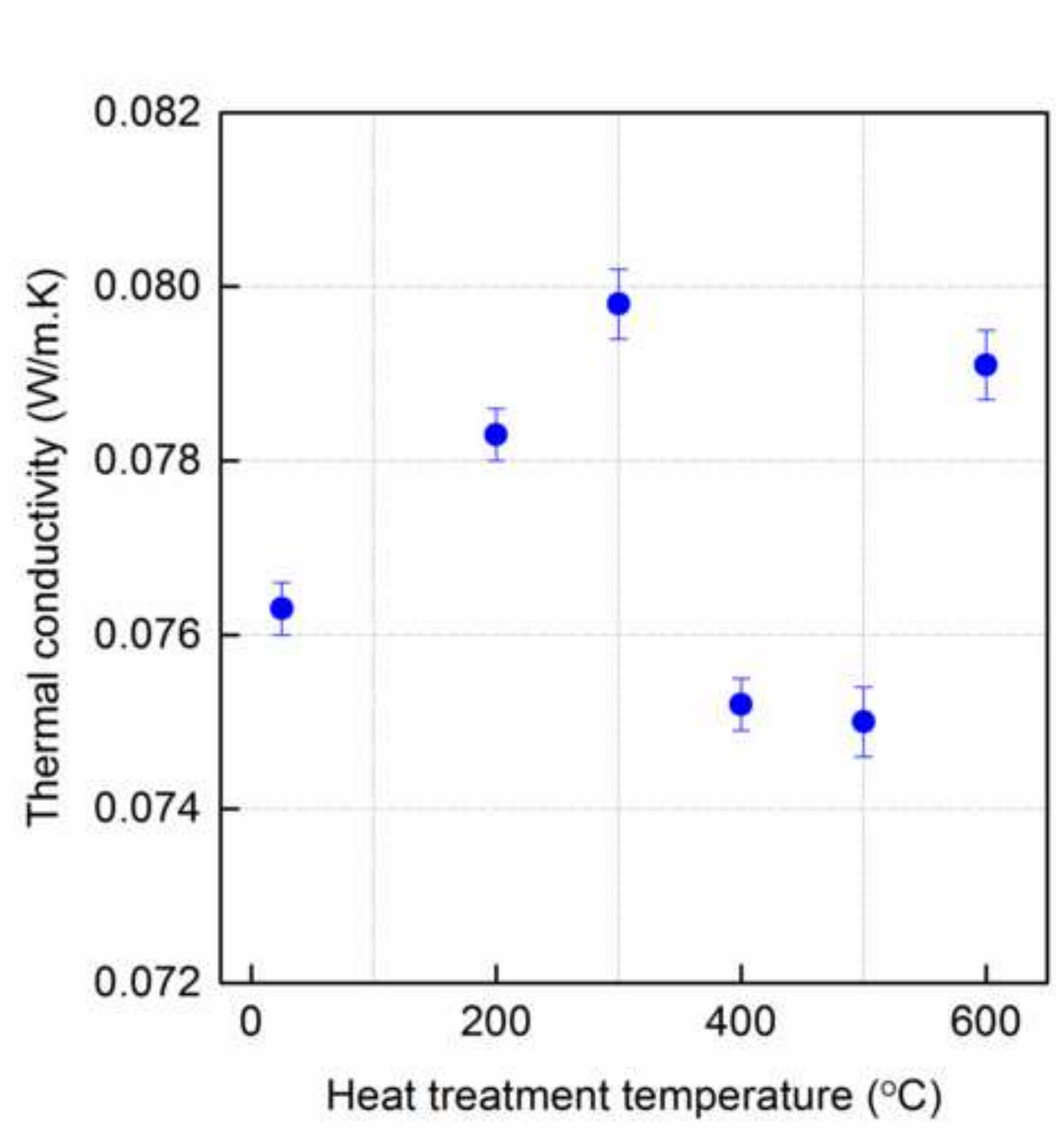

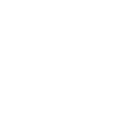

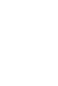

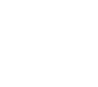

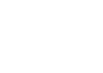

-

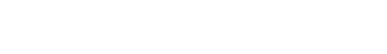
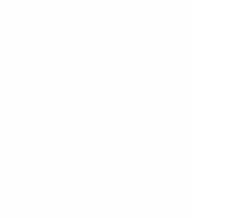

\section{Heat treatment temperature (OC)}

